\title{
Lexical characteristics of sound change
}

\author{
M ICHELE L. MOR R ISETTE
}

Indiana University, Bloomington, IN, USA

(Received 12 August 1997; accepted 2 July 1998)

\begin{abstract}
The purpose of this study was to determine the relationship between sound change and lexical structure in two children with functional phonological disorders. Specifically, the question of how sound change infuses through the developing lexicon was addressed. A chronology of phonemic acquisition for the children who participated has previously been documented. These archival data were now extended to evaluate lexical change relative to sounds acquired. Lexical change was examined through the parameters of neighbourhood density and word frequency. Results of this study revealed two converging patterns across children: (a) for each child there was one parameter (neighbourhood density or word frequency) of lexical change which held across all sounds acquired, and (b) for each child the alternative parameter patterned differentially by sound. This variability in lexical change was hypothesized to be associated with the relative degree of feature specification of the sounds acquired. This has theoretical implications for the overlay of phonological and lexical structure, and clinical potential for remediation of phonological disorders.
\end{abstract}

Keywords: phonological acquisition, lexical diffusion, sound change, word frequency, neighbourhood density.

\section{Introduction}

As a child acquires language, both the structure of the sound system and the structure of the lexicon must undergo change to become more like the ambient system. Specifically, the number of sounds that are used contrastively and the number of words in the lexicon will increase with development. While both sound change and lexical change in development have been documented, there has been no investigation of how the two domains may interact. Namely, how does sound change infuse through the developing lexicon?

Sound change in normally developing children and children with phonological disorders has been studied extensively in the literature (e.g. Locke, 1983; StoelGammon and Dunn, 1985). For children who are developing normally, sound

Address correspondence to: Michele L. Morrisette, Department of Speech and Hearing Sciences, Indiana University, 200 S. Jordan, Bloomington, IN 47405, USA. e-mail: mmorrise@indiana.edu 
change has been tracked longitudinally. The data are largely descriptive and have been documented, for example, using such methodologies as the phone tree (Ferguson and Farwell, 1975; Leonard, Newhoff and Mesalam, 1980; Stoel-Gammon and Cooper, 1984). In contrast, data on sound change for children with phonological disorders are primarily performance-based. Sound change in phonological disorders is a particularly relevant consideration because a fundamental goal of clinical treatment is to induce productive change. Change for these children has been documented as percentages of accuracy of sound production on probe measures, and includes evaluations of generalization to both treated and untreated sounds (e.g. Elbert and McReynolds, 1978; Gierut, 1998; McReynolds, 1972; Shelton and McReynolds, 1979 ). For both populations of children, two general patterns of sound change have emerged: across-the-board change and lexical diffusion (Labov, 1981). Across-theboard change involves simultaneous sound change in all relevant lexical items, whereas lexical diffusion involves gradual change in individual items of the lexicon on a case-by-case basis. While across-the-board change has been documented (Smith, 1973 ), the more prevalent pattern in acquisition involves lexical diffusion (Dinnsen, 1996). Thus, this study will be concerned primarily with lexically diffuse sound change.

Independent of sound change, the structural organization of spoken words in the mental lexicon of children has been investigated (Charles-Luce and Luce, 1990, 1995; Dollaghan, 1994; Logan, 1992). These studies have involved computational analyses of the similarity relations among words along two dimensions - neighbourhood density and word frequency. Words differing from one another by one phoneme are proposed to constitute 'similarity neighbourhood s' (Luce, 1986; Treisman, 1978). A one-phoneme difference could surface in the form of a substitution, an addition, or a deletion of a sound. For example, /deit/ 'date', /skest/ 'skate', /kæat/ 'cat' and /eit/ 'ate' are all neighbours of / ke1t/ 'Kate'. In addition to neighbourhood density, the lexical parameter of word frequency in the language has also been examined (Logan, 1992). These two factors have been the focus of studies in development because they have been found to be psychologically real in studies of spoken-word recognition in adults (e.g. Luce, 1986). Specifically, adult data have revealed that high-frequency words are recognized faster than low-frequency words, with words from low-density neighbourhoods recognized faster than those from high-density neighbourhoods. For children, results of computational analyses indicate that both the number and size of neighbourhood s in the mental lexicon increase with development (Charles-Luce and Luce, 1990, 1995; Dollaghan, 1994; Logan, 1992). These findings were consistent across both expressive and receptive domains. Also, the parameters of neighbourhood density and word frequency were found to be positively correlated (Logan, 1992), such that dense neighbourhoods are primarily composed of high-frequency words.

At first glance there would appear to be no relationship between across-theboard change, lexical diffusion, neighbourhood density, and word frequency in these two lines of study. However, some insight may come from historical sound change in fully developed systems. There have been a few studies which have evaluated which lexical items are most vulnerable to patterns of sound change in progress. An initial hypothesis was that high-frequency words were most susceptible to historical change (Fidelholz, 1975; Leslau, 1969), but more recently this hypothesis was challenged (Phillips, 1981). Contrary to early views, it was found that low-frequency words changed first in certain well-defined cases (Phillips, 1984). In particular, 
historical sound change involving phonotactic constraints was observed to first affect the least frequent words of the language. In contrast, surface phonetic changes governed by allophonic rules first affected the most frequent words of the language. Thus, word frequency may play a differential role in sound change, depending on the nature of change. These findings provide the only substantive information regarding how sound change may infuse through the lexicon, and may serve as the basis for similar predictions about phonological development. There are no available data on the role of neighbourhood density in sound change, albeit for developing or fully developed sound systems.

The purpose of this paper is to provide preliminary evidence concerning the possible relationship between sound change and lexical structure in development. Specifically, this study examines the parameters of neighbourhood density and word frequency as they relate to the lexically diffuse patterns of phonemic sound change for two children with phonological disorders. Following from historical sound change, one prediction is that low-frequency words will be most vulnerable to change as new phonemic distinctions are added to a child's repertoire. As for a possible relationship between sound change and neighbourhood density, this study will serve as the first evidence because no prior data are available.

\section{Participants and background information}

Two male children with phonological disorders, Subjects 4 and 2, aged 3;11 and 5;2 respectively, were selected from an archival database for purposes of this study because they demonstrated comparable pretreatment phonological systems. Both boys presented normal hearing (ASHA, 1985), non-verbal intelligence (Levine, 1986 ), and expressive (Hresko, Reid and Hammill, 1981; Newcomer and Hammill, 1988 ) and receptive (Dunn and Dunn, 1981) language abilities. Examination of each child's oral mechanism revealed normal structure and functioning (Robbins and Klee, 1987). Results of the Goldman Fristoe Test of Articulation (Goldman and Fristoe, 1986 ) indicated that Subject 4 performed at the 3 rd percentile and Subject 2 at the 2 nd percentile, relative to age- and gender-matched peers. For each child there were eight sounds excluded from the phonemic inventory across word positions. In-depth phonological analyses established the children's phonetic and phonemic sound inventories prior to treatment, as in table 1 (cf. Gierut, 1996). The phonetic inventory was based on a two time sound occurrence (Stoel-Gammon, 1985), whereas the phonemic inventory was based on a criterion of two unique minimal pairs (Gierut, Simmerman and Neumann, 1994).

Extensive phonological changes for these children were previously observed following clinical treatment, as documented in Morrisette and Gierut (1994) and Gierut and Morrisette (1996). To recapitulate briefly, clinical treatment was administered to both children in an experimental manipulation of the principle of laryngeal-supralaryngeal cyclicity. This principle proposes that phonological acquisition proceeds in a cyclic fashion with laryngeal (voice) then supralaryngeal (manner and/or place) distinctions emerging in turn. In the experimental manipulation, each child was taught a series of four sounds. Subject 4 was taught /f z s d/ 'in-phase', with alternating laryngeal and supralaryngeal phases relative to his pretreatment sound system. In comparison, Subject 2 was taught $/ \mathrm{sf} \theta \mathrm{J} /$ 'out-of-phase', with consecutive supralaryngeal phases relative to his pre-treatment sound system. Phonemic acquisition for each child was monitored and plotted longitudinally, 
Table 1. Pre-treatment phonetic and phonemic inventories

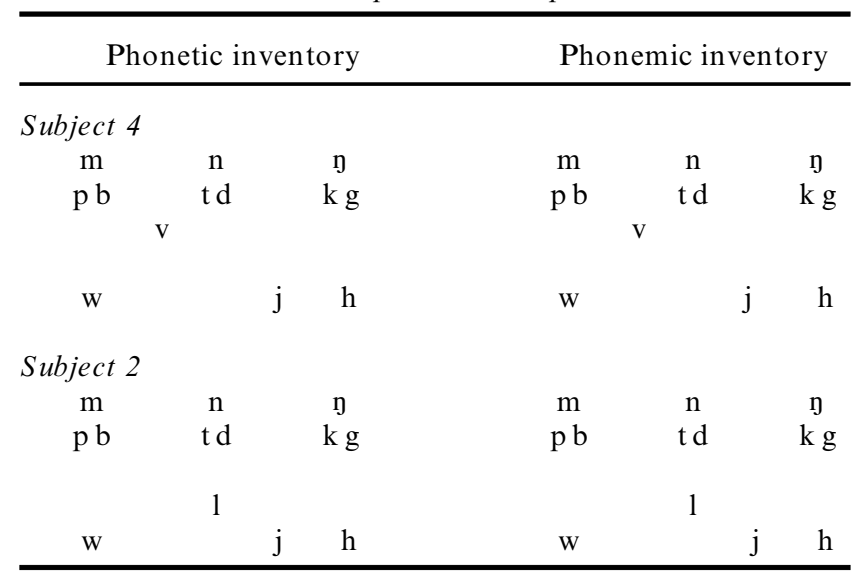

providing a chronology of the acquisition process. Phonemes acquired were determined on the basis of established criteria consisting of two unique sets of true minimal pairs at a given point in time with a minimum of $6 \%$ probe accuracy relative to the target sound system. Prior reports demonstrated that treatment 'out-of-phase' resulted in greater phonological change, where phase relationship was based on symmetry and asymmetry in inventory structure (Gierut, 1996). Consistent with this, Subject 4 acquired, in sequence, the sounds / $\mathrm{s} \mathrm{z} /$. Subject 2 acquired the sounds /zsf $\vee \theta$ J/. The present study utilized the sequences of sounds acquired by the children to establish the lexical characteristics of the particular probe words that changed.

\section{Methods}

\section{The PKP lexicon}

Changes in lexical items for both boys were sampled on the Phonological Knowledge Protocol (PKP; Gierut, 1985). The PKP was administered to each child 14 times across 9 months with approximately 18 days between samples. The PKP lexicon consists of 198 unique items which were originally chosen to sample productions of all target English consonants and glides in at least five words for each word position. The PKP is elicited as a spontaneous picture-naming task, and has been extensively used and documented in the literature as a means of monitoring phonological change associated with the elimination of phonological rules and phonotactic constraints (Elbert, Dinnsen, Swartzlander and Chin, 1990; Elbert, Powell and Swartzlander, 1991; Gierut, Elbert and Dinnsen, 1987; Powell, 1991; Tyler and Figurski, 1994).

For purposes of this study the items in the PKP lexicon were submitted for computational analysis to a database consisting of approximately 20000 entries found in the 1964 Merriam-Webster Pocket Dictionary (Nusbaum, Pisoni and Davis, 1984 ). This is a well-established adult database of lexical items which was chosen to avoid methodological difficulties with existing child databases (Dollaghan, 1994; Logan, 1992). Available child databases present inconsistencies in the range of ages sampled and further, procedures to develop these databases were not systematic. Importantly, for purposes of the present study, $60 \%$ of the PKP lexical items were not even sampled by other existing computational child databases (e.g. Dollaghan, 
1994 ). Despite certain inadequacies, adult and child databases have been shown to be comparable in composition (Jusczyk, Luce and Charles-Luce, 1994). The adult dictionary database, for example, contained 169 of the 198 lexical items (85\%) included in the PKP lexicon. It should be noted, however, that because the adult database is based on a 'pocket' dictionary, rather than a full set of lexical entries, some highly familiar words of the English language, such as 'you' or 'sun' were not available for analysis.

From the adult database the neighbourhood density and word frequency count of the 169 PKP lexical items available was obtained (Nusbaum et al., 1984). Each PKP lexical item was classified on the basis of neighbourhood density. High density was operationally defined as 10 or greater, based on distributional properties of the relevant PKP lexical items. Each PKP lexical item was also classified as high or low frequency. High frequency was operationally defined as a count of 100 or greater following Kučera and Francis (1967). Each lexical item in the PKP lexicon is listed in Appendix A with its corresponding neighbourhood density and word frequency count.

The PKP was originally designed to evaluate sound change and consequently, the proportion of high versus low density and high versus low frequency words varies by target sound. At first glance this may appear to be problematic; yet it is entirely consistent with the structure of the English language. Words are not equally balanced for neighbourhood density and word frequency by target sound, nor are they equally proportioned by syntactic class or phonological complexity (Crystal, 1995 ). Comparably, the PKP lexicon consists of $77 \%$ nouns, $15 \%$ verbs, $4 \%$ adjectives, $<1 \%$ adverbs, $1 \%$ prepositions, and $2.5 \%$ pronouns. Both monosyllabic and multisyllabic lexical items are included and words range in length from two to nine sounds.

\section{Analysis of change}

Items in the PKP lexicon that corresponded to each sound acquired by each child were examined for change. Specifically, each lexical item associated with the sounds acquired was examined to determine if productive sound change occurred. Change of a particular lexical item was defined on the conjunction of two criteria: (a) whether change to the ambient target production occurred, and (b) whether correct production was maintained across time. That is, production of lexical items had to be correct and to remain stable over time. For every PKP lexical item that changed, the properties of neighbourhood density and word frequency were then tallied by target sound acquired. Tables 2 and 3 illustrate these procedures.

As in table 2, the PKP sampled the target sound /z/ in a total of 11 lexical items. A child's production of $/ z /$ in each lexical item was then examined across the 14 sampling points to determine if it was produced target appropriately and further, whether the correct production was maintained across time. Data from Subject 4 are shown in table 3 . Here, three of the 14 sampling points are shown corresponding to pre-treatment, immediate post-treatment, and 2 months post-treatment points in time. The immediate post-treatment sampling point was 6 th out of the 14 samples, while pre-treatment and 2 months post-treatment were first and last, respectively. For Subject 4 the target sound /z/ was not produced correctly in any of the lexical items at either pre- or post-treatment points in time. Change to ambient target production did occur, however, for five lexical items at varying sampling points 
Table 2. PKP lexical items sampling /zl

\begin{tabular}{lcc}
\hline PKP lexical item & Neighbourhood density & Word frequency \\
\hline zebra & $\mathrm{L}$ & $\mathrm{L}$ \\
zipper & $\mathrm{L}$ & $\mathrm{L}$ \\
raisin & $\mathrm{L}$ & $\mathrm{L}$ \\
scissors & $\mathrm{L}$ & $\mathrm{L}$ \\
cheese & $\mathrm{H}$ & $\mathrm{L}$ \\
nose & $\mathrm{H}$ & $\mathrm{L}$ \\
noise & $\mathrm{L}$ & $\mathrm{L}$ \\
rose & $\mathrm{H}$ & $\mathrm{L}$ \\
buzz & $\mathrm{H}$ & $\mathrm{L}$ \\
these & $\mathrm{L}$ & $\mathrm{H}$ \\
theirs & $\mathrm{L}$ & $\mathrm{L}$ \\
Total & $7 \mathrm{~L} / 4 \mathrm{H}$ & $10 \mathrm{~L} / 11 \mathrm{H}$ \\
\hline
\end{tabular}

Note: $\mathrm{L}=$ low; $\mathrm{H}=$ high. High density was defined as a neighbourhood density of 10 or more neighbours. High frequency was defined as a word frequency count of 100 or greater.

Table 3. Sample analysis of change for Subject 4 for target sound /z/

PKP lexical item Pre-treatment Post-treatment Two months post-treatment Change?

\begin{tabular}{lllll}
\hline zebra & - & - & + & Yes \\
zipper & - & - & + & Yes \\
raisin & - & - & + & Yes \\
scissors & - & - & - & No \\
cheese & - & - & - & No \\
nose & - & - & - & No \\
noise & - & - & - & No \\
rose & - & - & + & Yes \\
buzz & - & - & - & Yes \\
these & - & - & - & No \\
theirs & - & - & & No \\
\hline
\end{tabular}

Note: Three of the 14 sampling points are shown for illustration purposes, with correct and stable production of the target sound in the lexical items indicated by $(+)$.

which occurred between post-treatment and 2 months post-treatment. Further, the change to accurate production of these lexical items was maintained until the final sampling point. Thus, the frequency and density characteristics of these lexical items met the operational definition of change and were included in the analysis. It should be mentioned that there were a few lexical items for each child where accuracy of production fluctuated across time; however, this pattern of change was not prevalent and is not reflected in the data to be presented. Finally, the neighbourhood density and word frequency of the five items that changed for Subject 4 were tallied and reported as percentages of accuracy. Thus, three of the seven low-density items ( $43 \%$ ) changed; two of the four high-density items changed (50\%); and five of the 10 low-frequency items (50\%) changed. The only high-frequency item sampled for /z/ evidenced no change in the child's productions. 


\section{Results}

The overall change in neighbourhood density and word frequency was plotted as a function of the sounds acquired in figures $1-4$. Results will be reported individually and then compared across children. The results of this study are descriptive in nature and are comparable to other developmental computational lexical studies where proportions have only been reported (Charles-Luce and Luce, 1990, 1995; Dollaghan, $1994)$. Chi-square statistical analyses were computed, but revealed no significant results. For completeness, the raw data for each child are presented in Appendix B.

\section{Subject 4}

Results for Subject 4 are shown in figures 1 and 2. Lexical items from high-density neighbourhoods underwent greater overall change than lexical items from lowdensity neighbourhoods. This pattern was consistent for all sounds acquired. Word frequency, on the other hand, evidenced variable change associated with place of articulation of the newly acquired sounds. For lexical items targeting the labial /f/, the greatest change occurred in high-frequency words. The reverse occurred for the coronals. For /s/ and /z/, the greatest change occurred in low-frequency words. Thus, neighbourhood density emerged as a stable parameter of change for this child. In contrast, word frequency was more variable across place of articulation.

\section{Subject 2}

Results of the computational analysis of lexical change for Subject 2 are shown in figures 3 and 4. Analysis of neighbourhood density revealed a differential patterning. For /s f v/, the greatest change occurred in high-density neighbourhoods, but for $/ \theta \mathrm{J} /$, the greatest change occurred in low-density neighbourhoods. This parameter functioned much like the parameter of word frequency for Subject 4. In terms of word frequency, high-frequency lexical items underwent the greatest overall change

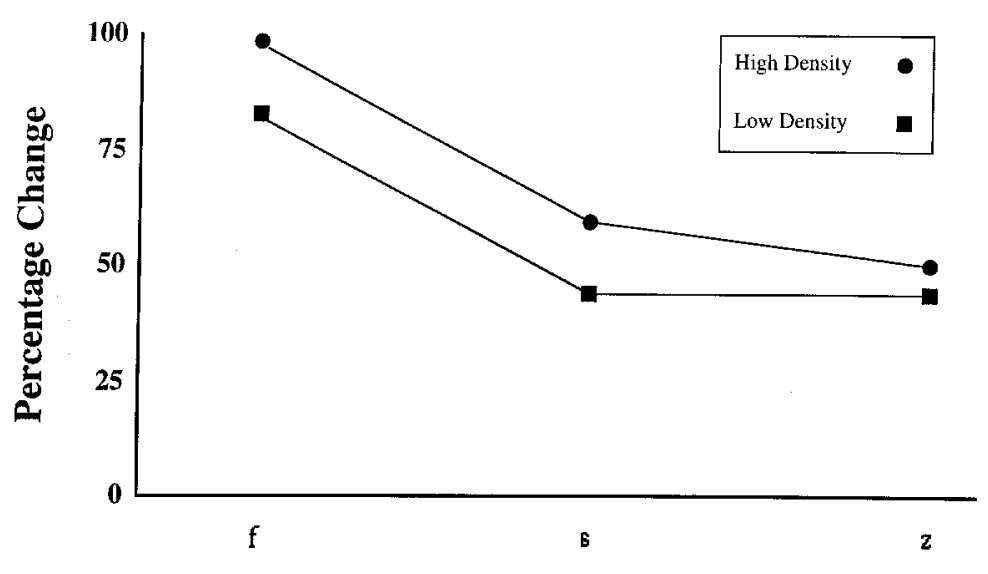

\section{Phonemes Acquired}

Figure 1. Percentages of change for high-and low-density lexical items plotted as a longitudinal function of sounds acquired by Subject 4. 


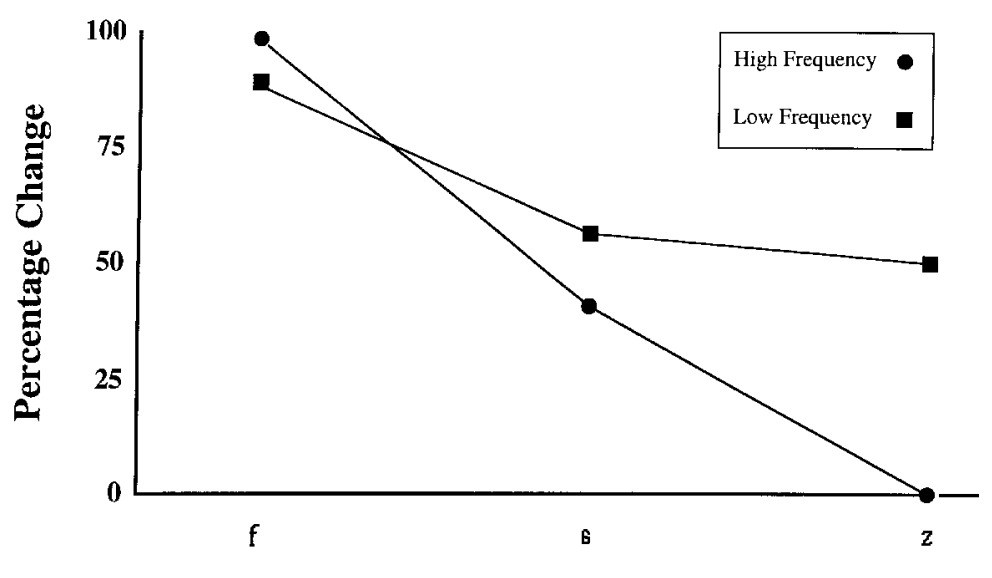

Phonemes Acquired

Figure 2. Percentages of change for high-and low-frequency lexical items plotted as a longitudinal function of sounds acquired by Subject 4.

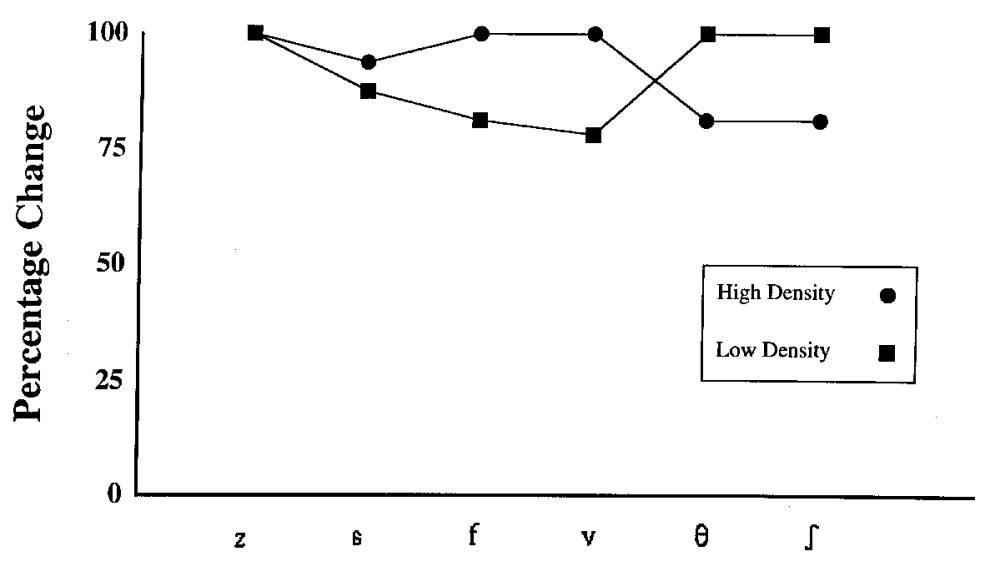

\section{Phonemes Acquired}

Figure 3. Percentages of change for high-and low-density lexical items plotted as a longitudinal function of sounds acquired by Subject 2.

for all sounds acquired, with the exception of /z/. All lexical items changed for /z/, therefore no pattern can be directly determined for this phoneme. Overall, however, for Subject 2, word frequency emerged as the more stable parameter of change, whereas neighbourhood density was more variable.

\section{Comparison across subjects}

Two patterns of responding emerged across the children. First, for each child there was one stable parameter of lexical change that held for all sounds acquired. For Subject 4 this stable parameter was high density; for Subject 2, high frequency. Second, the alternative lexical parameter was more variable. This was evidenced by the differential patterning of word frequency for the labial sound /f/ as compared 


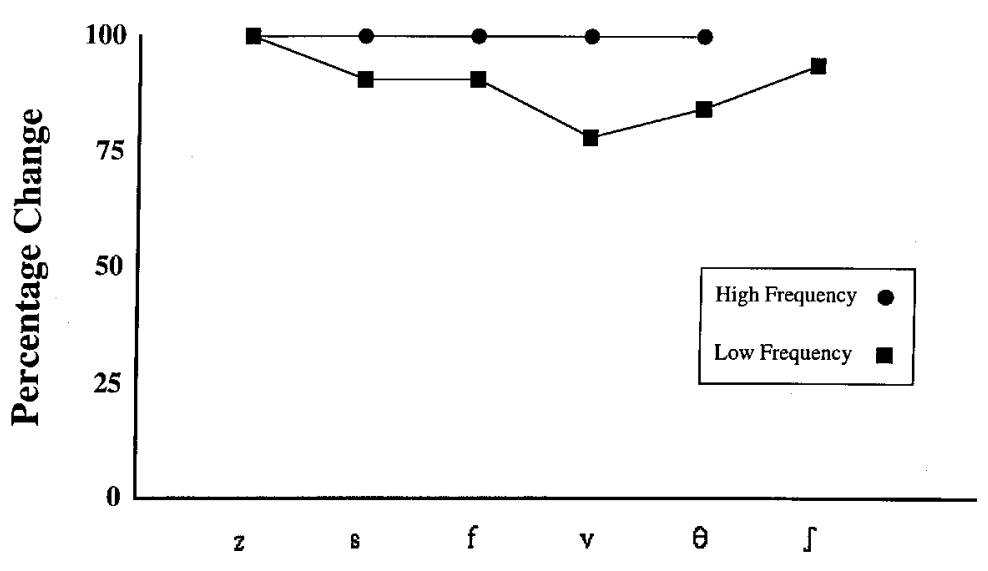

\section{Phonemes Acquired}

Figure 4. Percentages of change for high-and low-frequency lexical items plotted as a longitudinal function of sounds acquired by Subject 2. Note: The PKP lexicon did not sample any high-frequency lexical items for the phoneme $/ \mathrm{J} /$, hence there is no data point for this segment. This gap in the probe data does not, however, contradict the general pattern of change. Rather, there is evidence to suggest that the sounds $/ \theta /$ and $/ \mathrm{J} /$ should be examined together. First, both sounds were acquired within the same phase of acquisition (Gierut and Morrisette, 1996). Second, / $/$ / and / $/ \mathrm{J}$ pattern the same in regards to neighbourhood density.

to the coronals /s z/ for Subject 4. For Subject 2 the differential patterning was in neighbourhood density for the particular coronals $/ \theta \mathrm{f} /$ as compared to /f v s z/.

These results raise an interesting question of why one lexical parameter was variable: word frequency for Subject 4 and neighbourhood density for Subject 2 . One possible explanation comes by turning to a feature geometry account. Feature geometry is a phonological theory that has been used to account for the representation of subsegmental structure (Clements, 1985). Within this framework, features are organized hierarchically into tree structures. Certain branches of the tree structure stem from a root node, which essentially corresponds to the phoneme. The root node dominates other organizing or class nodes for voice, place, and manner. The organizing nodes further dominate groups of features. The features that extend from these organizing nodes are known as dependents of the node. The number of dependents of an organizing node determines the relative degree of specification for a given segment, with more dependents reflecting a greater degree of specification. For purposes of this paper, a generic view of feature geometry will be employed, with a radical underspecification of features (Archangeli, 1988). Within radical underspecification, all unmarked featural properties are universally underspecified, and only marked properties are geometrically represented.

By examining the labial and coronal sounds acquired by Subject 4 according to their feature geometries, it may be possible to explain differential patterning of sound change based on word frequency. The target geometries for the coronal and labial segments acquired by Subject 4 are shown in figures 5 and 6 . Notice that these segments differ in their relative degree of feature specification. Coronals are universally considered underspecified for place; thus there are no dependents of this node. For the labial fricative the Place node dominates the property Labial. Thus, 


\section{/ S Z /}

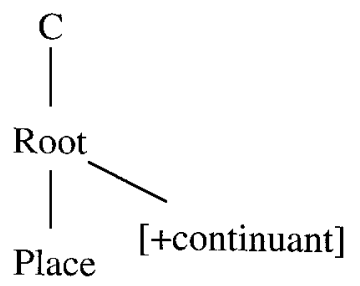

Figure 5. Feature geometry for coronal segments /s/ and /z/.

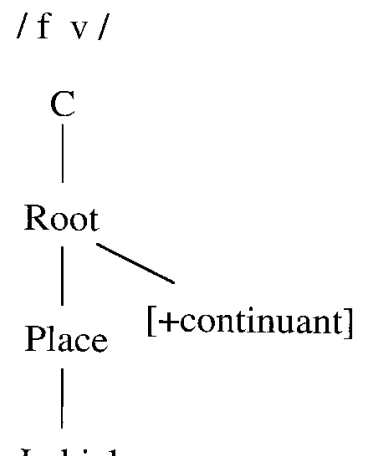

Labial

Figure 6. Feature geometry for labial segments /f/ and /v/.

for this child, the labial carried a greater degree of specification relative to the other coronals in the system as evidenced by more dependents. In sum, productive sound change in the relatively more specified segment/f/ was implemented in high-frequency words, but change in the less specified segments /s z/ occurred in low-frequency words.

Results for Subject 2 may also be explained within this account. Representations for the segments $/ \theta /$ and $/ \mathrm{J} /$ are shown in figures 7 and 8 , to be compared with

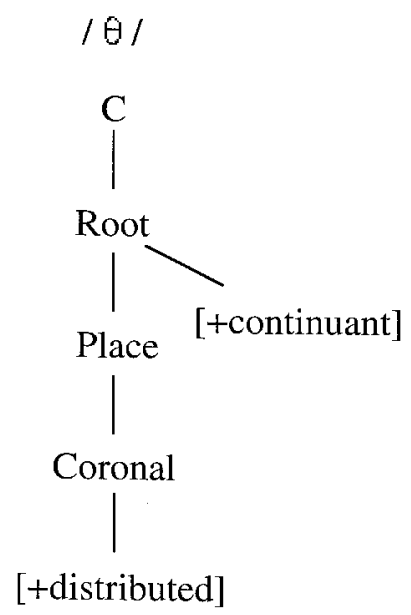

Figure 7. Feature geometry for coronal segment $/ \theta /$. 


\section{$/ \int /$}

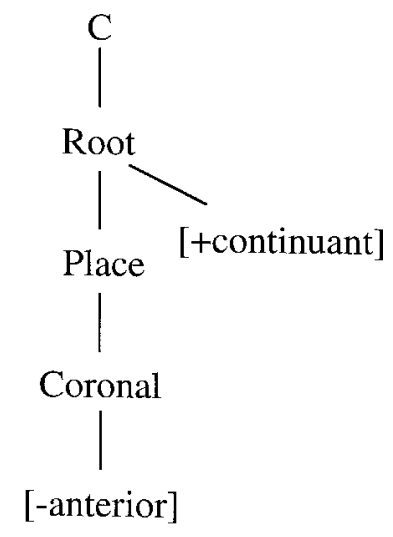

Figure 8. Feature geometry for coronal segment / $\mathrm{f} /$.

figures 5 and 6 . Notice that, although $/ \theta /$ and $/ \mathrm{f} /$ are coronal, they carry a relatively greater degree of specification than the coronals /s z/ because they have a greater number of dependents. For the segment $/ \theta /$, coronal place is further specified by the feature $[+$ distributed $] / \delta /$ is further specified by the feature [ - anterior $]$. Similarly, $/ \theta /$ and $/ \mathrm{S} /$ also carry a relatively greater degree of specification than the labials /f v/. The labials have no further featural dependents of place, but $/ \theta \mathrm{J} / \mathrm{do}$. Thus, productive sound change in the relatively more specified segments $/ \theta \mathrm{J} /$ was implemented in low-density words, but change in the less specified segments /f v s z/ occurred in highdensity words.

In sum, the variable patterns of lexical change for both children can be accounted for by appealing to feature geometry and underspecification. Lexical variability is hypothesized to be associated to the relative degree of feature specification for the segments which underwent change. Importantly, the degree of specification assigned to each of the segments was relative to the child's phonological system as sounds were added to the inventory. This explains why labial carried a greater degree of specification for Subject 4, but not for Subject 2 (cf. Bernhardt and Stoel-Gammon, 1996; Rice and Avery, 1995 for further discussion of child-specific default features).

These results are further illustrated in figures 9 and 10. These figures are schematic

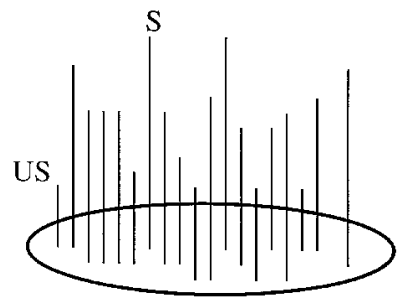

Figure 9. Schematic of a neighbourhood. Neighbours are represented by the number of vertical lines. Word frequency is represented by the height of the vertical lines. For Subject 4 , change in high-frequency lexical items from high-density neighbourhoods was associated with specified (S) phonological properties. Change in low-frequency lexical items from high-density neighbourhoods was associated with underspecified (US) phonological properties. 

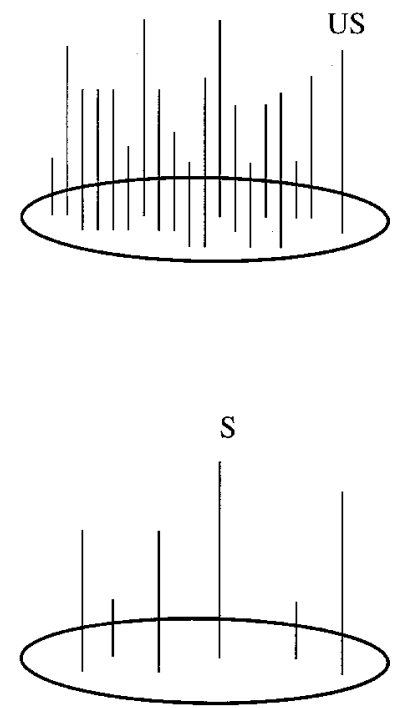

Figure 10. For Subject 2, change in high-frequency lexical items from low-density neighbourhoods was associated with specified phonological properties. Change in highfrequency lexical items from high-density neighbourhoods was associated with underspecified phonological properties.

of a neighbourhood. Neighbourhood density and word frequency are represented by vertical lines. The number of vertical lines represents neighbourhood density. The height of the vertical lines represents word frequency. For Subject 4, change consistently occurred in high-density neighbourhoods, but change in high-frequency words from dense neighbourhoods was associated with specified phonological properties, whereas change in low-frequency words from dense neighbourhoods was associated with underspecified phonological properties. In comparison, Subject 2 consistently demonstrated change for high-frequency words. The high-frequency words associated with specified phonological properties came from sparse neighbourhoods, but those associated with underspecified phonological properties came from dense neighbourhoods.

\section{Discussion}

The results of this study provide preliminary evidence of a potential relationship between sound change and lexical structure. In particular, converging patterns of sound change through the lexicon were observed for two children with phonological disorders. Both children demonstrated one stable and one variable lexical parameter of change for sounds acquired. Variability in lexical change was hypothesized to be associated to the relative degree of feature specification of the sounds acquired.

The results diverge somewhat from patterns of historical sound change, particularly as they relate to word frequency effects. Recall that studies that have investigated historical sound change in fully developed systems have found that changes involving phonotactic constraints occur in low-frequency words (Phillips, 1984). In the present study only phonemic sound changes involving phonotactic constraints were examined. Presumably then, we might expect lexical change to occur in lowfrequency words for these children. Yet, for one child (Subject 2), phonemic change 
was primarily associated with only high-frequency lexical items, while phonemic change for the other child (Subject 4) was associated with both high- and lowfrequency lexical items. Thus, the patterns observed for historical sound change did not directly parallel those in the developing lexicons of the two children of the present study. Further research will be needed to determine if the lexical patterns observed for historical sound changes are upheld in acquisition. Research of this type could be implemented in within- and across-subject comparisons. Either type of comparison will need to involve the examination of lexical change for those error patterns related to allophonic rules as opposed to error patterns stemming from phonotactic constraints in order to provide further insight into the role of word frequency in lexical change.

R esearch will also need to determine the nature and range of individual differences observed in the infusion of sound change through the lexicon. In particular, it is not known why the stable parameter of change was neighbourhood density for one child of this study, and word frequency for the other. Perhaps, children may have different choices regarding their approach to change. Alternatively, individual differences may represent different developmental patterns associated with age. Although the two children of the present study had similar pretreatment phonological inventories, they did differ in age: Subject 4 was $3 ; 11$ and Subject 2 was 5;2. In order to disambiguate the individual differences found in the present study, it will be important to examine a wider range of children that vary in age and phonological systems.

Future investigation regarding clinical treatment is also warranted. The patterns observed in the present study suggest that the lexical parameters of neighbourhood density and word frequency are psychologically real as in adult spoken language processing. If this is true, then it should be possible to manipulate these parameters in clinical treatment. For example, differential results may be obtained by treatment manipulations of high/low density versus high/low frequency words (Gierut, Morrisette and Champion, 1998). The behavioural effects of lexical parameters in sound change may hold important implications for the efficacy of phonological treatment.

Finally, while this study serves as a first step to uncovering the relationship between phonological and lexical change in acquisition, other variables will need to be examined. For example, the characteristics of neighbourhood density and word frequency are examined here, but syntactic class and word length may also play an interactive role in determining how sound change infuses through the developing lexicon. Further investigation may uncover the exact nature of the interaction between these variables in acquisition.

\section{Acknowledgements}

This research was supported in part by grants from the National Institutes of Health (DC01694, DC00012) to Indiana University. The research was completed in partial fulfilment of the requirements for the Master of Arts degree. I thank the chairperson Judith A. Gierut, and members of the thesis committee, Daniel A. Dinnsen, Karen Forrest, and David Pisoni, for helpful comments and assistance throughout this project. David Pisoni made the adult dictionary database available for our use, and Luis Hernandez assisted in computational analyses. 


\section{References}

Archangeli, D., 1988, Aspects of underspecification theory. Phonology, 5, 183-207.

ASHA Commmittee on Audiologic Evaluation, 1985, Guidelines for identification audiometry. ASHA, 27, 49-52.

Bernhardt, B. and Stoel-Gammon, C., 1996, Underspecification and markedness in normal and disordered phonological development. In C. E. Johnson and J. H. V. Gilbert (Eds), Children's Language (Mahwah, NJ: Erlbaum), pp. 33-53.

Charles-Luce, J. and Luce, P. A., 1990, Similarity neighbourhoods of words in young children's lexicons. Journal of Child Language, 17, 205-215.

Charles-Luce, J. and Luce, P. A., 1995, An examination of similarity neighbourhoods in young children's receptive vocabularies. Journal of Child Language, 22, 727-736.

Clements, G. N., 1985, The geometry of phonological features. Phonology, 2, 225-252.

Crystal, D., 1995, The Cambridge Encyclopedia of the English Language (New York: Cambridge University Press).

Dinnsen, D. A., 1996, Context-sensitive underspecification and the acquisition of phonemic contrasts. Journal of Child Language, 23, 57-79.

Dollaghan, C. A., 1994, Children's phonological neighbourhoods: half empty or half full? Journal of Child Language, 21, 257-272.

Dunn, L. M. and Dunn, L. M., 1981, Peabody Picture Vocabulary Test-Revised (Circle Pines, MN: American Guidance Service).

Elbert, M. and McReynolds, L. V., 1978, An experimental analysis of misarticulating children's generalization. Journal of Speech and Hearing Research, 21, 136-150.

Elbert, M., Dinnsen, D. A., Swartzlander, P. and Chin, S. B., 1990, Generalization to conversational speech. Journal of Speech and Hearing Disorders, 55, 694-699.

Elbert, M., Powell, T. W. and Swartzlander, P., 1991, Toward a technology of generalization. How many exemplars are sufficient? Journal of Speech and Hearing Research, 34, 81-87.

Ferguson, C. A. and FARwell, C. B., 1975, Words and sounds in early language acquisition: English initial consonants in the first fifty words. Language, 51, 419-439.

Fidelholz, J., 1975, Word frequency and vowel reduction in English. Chicago Linguistic Society, 11, 200-213.

Gierut, J. A., 1985, On the relationship between phonological knowledge and generalization learning in misarticulating children (Doctoral dissertation, Indiana University Linguistics Club).

Gierut, J. A., 1996, An experimental test of phonemic cyclicity. Journal of Child Language, 23, 81-102.

Gierut, J. A., 1998, Treatment efficacy: functional phonological disorders in children. Journal of Speech, Language and Hearing Research, 41, S85-100.

Gierut, J. A. and Morrisette, M. L., 1996, Triggering a principle of phonemic acquisition. Clinical Linguistics and Phonetics, 10, 15-30.

Gierut, J. A., Elbert, M. and Dinnsen, D. A., 1987, A functional analysis of phonological knowledge and generalization learning in misarticulating children. Journal of Speech and Hearing Research, 30, 462-479.

Gierut, J. A., Morrisette, M. L. and Champion, A. H., 1998, Lexical constraints in phonological acquisition. Journal of Child Language (In press).

Gierut, J. A., Simmerman, C. L. and Neumann, H. J., 1994, Phonemic structures of delayed phonological systems. Journal of Child Language, 21, 291-316.

Goldman, R. and Fristoe, M., 1986, Goldman-Fristoe Test of Articulation (Circle Pines, MN: American Guidance Service).

Hresko, W. P., Reid, D. K. and Hammill, D. D., 1981, The Test of Early Language Development (A ustin, TX: Pro-Ed).

JusczyK, P. W., Luce, P. A. and Charles-Luce, J., 1994, Infants' sensitivity to phonotactic patterns in the native language. Journal of Memory and Language, 33, 630-645.

Kučera, H. and Francis, W. N., 1967, Computational Analysis of Present-day American English (Providence, R I: Brown University Press).

Labov, W., 1981, Resolving the Neogrammarian controversy. Language, 57, 267-309.

Leonard, L. B., Newhoff, M. and Mesalam, L., 1980, Individual differences in early child phonology. Applied Psycholinguistics, 1, 7-30. 
Leslau, W., 1969, Frequency as determinant of linguistic change in the Ethiopian languages. Word, 25, 180-189.

Levine, M. N., 1986, Leiter International Performance Scale: A handbook (Chicago, IL: Stoelting).

Locke, J. L., 1983, Phonological Acquisition and Change (New York: Academic Press).

LogAn, J. S., 1992, A computational analysis of young children's lexicons (Technical report No. 8) (Bloomington, IN: Speech Research Laboratory, Indiana University).

Luce, P. A., 1986, Neighborhoods of words in the mental lexicon (Technical Report No. 6) (Bloomington, IN: Speech Research Laboratory, Indiana University).

McReynolds, L. V., 1972, Articulation generalization during articulation training. Language and Speech, 15, 149-155.

Morrisette, M. L. and Gierut, J. A., 1994, Triggering cyclicity in phonemic acquisition. Poster session presented at the Fourth Annual Congress of the International Clinical Linguistics and Phonetics Association, New Orleans, LA, November.

Newcomer, P. L. and Hammill, D. D., 1988, Test of Language Development-2 Primary (Austin, TX: Pro-Ed).

Nusbaum, H. C., Pisoni, D. B. and Davis, C. K., 1984, Sizing up the Hoosier mental lexicon. Research on Spoken Language Processing, 10, 357-376.

Phillips, B. S., 1981, Lexical diffusion and southern tune, duke, news. American Speech, 56, 72-78.

Phillips, B. S., 1984, Word frequency and the actuation of sound change. Language, 60, $320-342$.

Powell, T. W., 1991, Planning for phonological generalization: an approach to treatment target selection. American Journal of Speech-Language Pathology, 1, 21-27.

Rice, K. and Avery, P., 1995, Variability in a deterministic model of language acquisition: a theory of segmental elaboration. In J. Archibald (Ed.), Phonological Acquisiton and Phonological Theory (Hillsdale, NJ: Erlbaum), pp. 23-42.

Robbins, J. and KLEE, T., 1987, Clinical assessment of oropharyngeal motor development in young children. Journal of Speech and Hearing Disorders, 52, 271-277.

Shelton, R. L. and McReynolds, L. V., 1979, Functional articulation disorders: preliminaries to treatment. In N. Lass (Ed.), Speech and Language: Advances in Basic Research and Practice (New York: Academic Press), pp. 1-111.

Smith, N. V., 1973, The Acquisition of Phonology: A Case Study (Cambridge: Cambridge University Press).

Stoel-Gammon, C., 1985, Phonetic inventories 15-24 months: a longitudinal study. Journal of Speech and Hearing Research, 28, 505-512.

Stoel-Gammon, C. and Cooper, J. A., 1984, Patterns of early lexical and phonological development. Journal of Child Language, 11, 247-271.

Stoel-Gammon, C. and Dunn, C., 1985, Normal and Disordered Phonology in Children (Austin, TX: Pro-Ed).

Treisman, M., 1978, A theory of the identification of complex stimuli with an application to word recognition. Psychological Review, 85, 525-570.

Tyler, A. A. and Figurski, G. R., 1994, Phonetic inventory changes after treating distinctions along an implicational hierarchy. Clinical Linguistics and Phonetics, 8, 91-108.

\section{Appendix A}

PKP lexical item

Neighbourho od density

Word frequency

angel

back

badge

bag 
PKP lexical item

Neighbourho od density

Word frequency

bed

behind

25

127

big

20

bite

*

360

blow

15

33

bluehouse

*

*

book

boot

bridge

6

98

brother

73

brush

0

2

bubble

5

12

bus

10

35

button

20

10

buzz

6

13

cage

15

17

call

26

188

camera

0

$*$

carrot

20

catch

20

chair

chalk

13

cheese

13

chicken

chip

coat

31

cob

colour

22

8

comb

24

cough

cracker

11

2

crash

13

crayon

cup

2

18

25

deer

*

36

$*$

4

66

3

9

*

17

4

1

141

6

7

1

20

1

45

192

dog

8

$*$

done

30

door

13

321

dress

312

drive

9

67

9

duck

105

25

24

eat

elephant

eraser

face 
PKP lexical item

fat

father

feather

finger

fire

fish

five

flower

forehead

frog

game

gate

giraffe

girl

glove

goat

Goofy

grasshopper

grow

gum

gun

hammer

happy

hat

hide

hill

house

hug

ice

jail

jeep

jelly

juice

jump

kitchen

knife

ladder

lady

laugh

leaf

leg

light

lotion

marshmallow

money

moon
Neighbourho od density

Word frequency

28

60

6

183

8

6

1

40

22

187

13

35

12

286

5

23

16

4

20

123

*

*

1

16

220

3

26

$*$

$*$

18

16

20

6

3

34

21

33

7

21

16

*

$*$

5

13

8

0

8

10

6

19

25

15

35

5

0

10

21
63

9

6

*

*

14

118

9

98

56

22

72

591

3

45

$*$

*

3

11

24

90

76

19

80

28

12

58

333

8

1

265

60 
PKP lexical item

Neighbourho od density

Word frequency

mother

mouse

4

14

216

mouth

7

10

mud

20

nail

26

03

noise

4

6

nose

nothing

18

0

onion

open

orange

other

over

page

paint

pants

peach

piano

picture

pie

pig

pinch

pocket

potato

punch

push

rabbit

rain

raisin

read

ride

ring

robe

rock

roof

rose

rub

run

Santa

scissors

seven

sew

shampoo

shave

shirt

shoe

\section{1}

4

2

5

10

16

12

11

22

0

2

$*$

19

10

7

0

8

5

*

38 
PKP lexical item

\begin{tabular}{|c|c|c|}
\hline shovel & 4 & 5 \\
\hline sleep & 13 & 65 \\
\hline snow & $*$ & $*$ \\
\hline soap & 21 & 22 \\
\hline sock & 26 & 4 \\
\hline soup & 22 & 16 \\
\hline star & 12 & 25 \\
\hline stove & 8 & 15 \\
\hline sun & $*$ & $*$ \\
\hline swim & 11 & 15 \\
\hline tail & 30 & 45 \\
\hline tear & $*$ & $*$ \\
\hline teeth & 12 & 103 \\
\hline thank you & $*$ & * \\
\hline that & 14 & 10595 \\
\hline theirs & 1 & 21 \\
\hline them & 5 & 1789 \\
\hline there & $*$ & $*$ \\
\hline these & 9 & 1573 \\
\hline thief & 8 & 8 \\
\hline thirsty & $*$ & $*$ \\
\hline throw & $*$ & * \\
\hline thumb & 15 & 10 \\
\hline thunder & 3 & 14 \\
\hline tiger & 0 & 7 \\
\hline toes & $*$ & $*$ \\
\hline tongue & 16 & 35 \\
\hline tooth & 14 & 20 \\
\hline towel & 9 & 6 \\
\hline treehouse & $*$ & $*$ \\
\hline tub & 17 & 13 \\
\hline vacuum & 0 & 20 \\
\hline valentine & 0 & 2 \\
\hline van & 12 & 32 \\
\hline vanilla & 0 & 1 \\
\hline vegetable & 0 & 10 \\
\hline wagon & 0 & 55 \\
\hline wash & 7 & 37 \\
\hline watch & 5 & 81 \\
\hline water & 3 & 22 \\
\hline wave & $*$ & $*$ \\
\hline web & 10 & 6 \\
\hline window & 5 & 119 \\
\hline wreath & 17 & 8 \\
\hline yard & 10 & 35 \\
\hline yawn & 12 & 2 \\
\hline
\end{tabular}


PKP lexical item

Neighbourhood density

Word frequency

yellow

yes

7

55

you

9

12

zebra

Ziggy

zipper

zipping

zoo

*

*

1

1

*

*

6

1

$*$

$*$

$*$

*

Note: The symbol * indicates that the lexical item was not catalogued in the 20000 -word dictionary database.

\section{Appendix B}

\begin{tabular}{|c|c|c|c|c|c|c|c|c|}
\hline \multirow[b]{2}{*}{ Phonemes acquired } & \multicolumn{8}{|c|}{ Number of lexical items changed } \\
\hline & \multicolumn{2}{|c|}{ Low D } & \multicolumn{2}{|c|}{ High D } & \multicolumn{2}{|c|}{ Low F } & \multicolumn{2}{|c|}{ High $\mathrm{F}$} \\
\hline \multicolumn{9}{|l|}{ Subject 4} \\
\hline $\mathrm{f}$ & 8 & $(10)$ & 9 & $(9)$ & 13 & $(15)$ & 4 & (4) \\
\hline $\mathrm{s}$ & 3 & $(7)$ & 7 & (12) & 8 & (14) & 2 & (5) \\
\hline $\mathrm{z}$ & 3 & (7) & 2 & (4) & 5 & $(10)$ & 0 & (1) \\
\hline \multicolumn{9}{|l|}{ Subject 2} \\
\hline Z & 7 & (7) & 4 & (4) & 10 & $(10)$ & 1 & (1) \\
\hline $\mathrm{s}$ & 6 & (7) & 11 & (12) & 12 & (14) & 5 & (5) \\
\hline $\mathrm{f}$ & 8 & $(10)$ & 9 & (9) & 13 & (15) & 4 & (4) \\
\hline $\mathrm{v}$ & 7 & (9) & 4 & (4) & 7 & (9) & 4 & (4) \\
\hline$\theta$ & 3 & (3) & 4 & (5) & 5 & (6) & 2 & (2) \\
\hline $\int$ & 7 & (7) & 4 & $(5)$ & 11 & $(12)$ & 0 & $(0)$ \\
\hline
\end{tabular}

Note: $\mathrm{D}=$ neighbourhood density; $\mathrm{F}=$ word frequency count. Numbers shown in parentheses indicate possible number of lexical items in the PKP lexicon which sample each phoneme. 